\title{
Comparison between sensory evaluation and SPME GC-MS in Brazilian's sparkling wines
}

\author{
E. Gabbardo ${ }^{1}$, E. Celotti ${ }^{2}$, and M. Gabbardo ${ }^{3}$ \\ ${ }^{1}$ UFPEL, 96160-000 Capão do Leão, RS, Brazil \\ ${ }^{2}$ UNIUD Departimento di Scienza degli Almineti, 33100 Udine-FVG, Italy \\ ${ }^{3}$ UNIPAMPA Campus Dom Pedrito, 96450-00 Dom Pedrito, RS, Brazil
}

\begin{abstract}
Looking for understand which is the profile aromatic's complexity in Brazilian's sparkling wines, this study's objective was to evaluate 5 samples of commercial sparkling wines by sensory analysis, and also by a gas chromatography (GC), and mass spectrometry (MS). At the sensory analysis, in Brazil's panel, from a total of 5 sparkling samples, were made 155 determinations of aromas found at wines, with 31 distinct descriptors. The same process was realized at the Italian's panel, and at this time we found 188 determinations of aromas from all the 5 sparkling's samples, with 31 distinct descriptors. For the volatile compounds analysis the gas chromatography-mass spectrometry (GC-MS) identified 26 compounds, the most of them have a fruity characteristic. This study demonstrated the Brazilian's sparkling wines have a profile fruity and floral, with maturation notes.
\end{abstract}

\section{Introduction}

Complexity is a term widely used in beverage degustation, and is considered a positive characteristic and desirable in wines. But, what is really is complexity? [1] respond this question saying that complexity is an associative perception of multiple elements, especially from several individual compounds synergy.

The same authors [1] also say that is possible to considerate as a complexity indicative, the number of volatile compounds that can be detected on a wine. In other words, how bigger concentration and quantity of aromatic compounds, bigger is the complexity perception.

The composition of volatile compounds in wines is result of several factors, like the grape cultivar, the geographic origin and winemaking technology [2].

To evaluate the wine's complexity, is possible choose a chemical analysis, to identification of volatile compounds. Or also evaluate the human perception of the synergy by a sensory analyses. [3] say that the relation between the both analysis, chemical and sensory, in wines, is an extensive search area in enology.

At sensory, many authors indicate a panel of trained evaluators like an appropriate option to analyze the parameters of quality in wines [3-6].

[7] affirm that the volatile compounds present in wine, although in small concentrations, play an important role in the sensory quality of wine. The same authors say that the solid phase microextration (SPME) is an excellent alternative for extraction of these compounds. Other authors point out its efficiency when associated with gas chromatographic detection [8-11].

The phenomenon of Brazilian sparkling wine in the local market shows an expressive growth of production and consumption in a small space of time. [12] show that in the last 10 years there has been a $280 \%$ increase in the production of sparkling wines, $80 \%$ of which is for domestic consumption in the country. [13] suggest that this increase of production and consumption is a consequence of the increase of the quality and typicality of the products.

To compare the sensory evaluation of Brazilian sparkling wines with analysis of their volatile compounds by gas chromatography coupled to mass spectrometry (GC-MS) can indicate the complexity of the aroma of Brazilian sparkling wines.

\section{Material and methods}

In this work 5 samples of Brazilian sparkling wines, commercially available in the national market, were analyzed. All the wines were classified as Brut, and were elaborated from the cultivars Pinot Noir, Chardonnay and Riesling Italic.

The analysis of the volatile fraction of the sparkling wines was determined via SPME-GC-MS, according to the method described by [12], using a three-phase $2 \mathrm{~cm}$ fiber (Supelco) at a sampling temperature of $40^{\circ} \mathrm{C}$ for 15 minutes.

Samples were analyzed in duplicate using a GC system (Agilent Technologies Italia S.p.A., Cernusco sul Naviglio, MI, Italy) that comprised an auto sampler (Agilent PAL RSI 85) with 45 slots, a gas chromatograph (GC Agilent 7890B) equipped with two columns (DB-5MS and VFWAX, both $30 \mathrm{~m} \times 0.25 \mathrm{~mm}$ i.d., film thickness $0.5 \mu \mathrm{m}$ ), and a mass spectrometer (Agilent 5977A) that included an electron impact source and a quadrupole analyzer. The conditions for GC included an isothermal start at $40{ }^{\circ} \mathrm{C}$ for 5 minutes, followed by a temperature ramp from $40^{\circ} \mathrm{C}$ to $240{ }^{\circ} \mathrm{C}$ at $4{ }^{\circ} \mathrm{C} / \mathrm{min}$ and a final isothermal holding time of 10 minutes at $240^{\circ} \mathrm{C}$. 
Table 1. Aromatic compounds and mean values that were quantified using SPME-GC-MS for each evaluated Brazilian sparkling wine.

\begin{tabular}{|c|c|c|c|c|c|c|c|}
\hline \multirow{2}{*}{ Chemical Compounds } & \multirow{2}{*}{$\mathbf{R T} \dagger$} & \multirow{2}{*}{ Wine aromatic descriptor $\ddagger$} & \multicolumn{5}{|c|}{ Mean concentration of aromatic compounds $\left(\mathrm{mg}^{-\mathrm{L}^{-1}}\right)$} \\
\hline & & & SW1 & SW2 & SW3 & SW4 & SW5 \\
\hline Ethyl acetate & 4.083 & $\begin{array}{l}\text { Fruity (apple, raspberry and } \\
\text { strawberry) }\end{array}$ & 21.75 & 21.65 & 26.67 & 19.82 & 17.03 \\
\hline Ethyl butanoate & 8.688 & Pineapple, apple and cheese & 0.89 & 0.94 & 1.01 & 0.83 & 1.57 \\
\hline 1-Propanol & 8.79 & Alcoholic & 0.86 & 1.74 & 1.50 & 0.75 & 0.99 \\
\hline Isobutanol & 10.885 & Alcoholic & 3.78 & 2.89 & 2.71 & 3.00 & 7.89 \\
\hline Isoamyl acetate & 11.93 & Banana or pear & 0.80 & 1.85 & 1.76 & - & - \\
\hline Isoamyl alcohol & 15.276 & Malty, enamel, pungente & 66.75 & 58.43 & 46.74 & 52.91 & 74.75 \\
\hline Ethyl hexanoate & 16.219 & $\begin{array}{l}\text { Floral/fruity (pineapple, } \\
\text { blackberry, apple and strawberry) }\end{array}$ & 3.80 & 6.92 & 6.58 & 5.05 & 4.83 \\
\hline Ethyl lactate & 20.253 & Butter & 6.96 & 0.84 & 2.54 & 5.42 & 1.55 \\
\hline 1-Hexanol & 20.493 & Freshly cut grass & 5.25 & 3.28 & 3.37 & 4.24 & 3.40 \\
\hline Ethyl octanoate & 23.318 & Sweet aromas & 12.24 & 18.32 & 26.55 & 12.50 & 6.23 \\
\hline Furfural & 24.45 & Yeast & 1.98 & 1.87 & 1.92 & 1.50 & 1.23 \\
\hline 2-ethyl-hexanol & 25.059 & Earthy, lightly floral & 1.08 & - & - & 0.87 & 0.86 \\
\hline 2, 3-butanediol & 26.682 & Sweet & - & 1.12 & 0.70 & - & - \\
\hline Isoamyl lactate & 27.637 & Fruity & - & - & 0,64 & - & - \\
\hline 2-ethyl-furanoate & 29.34 & Aged & - & 0.74 & - & - & - \\
\hline Ethyl decanoate & 29.663 & Floral & 4.88 & 5.13 & 13.70 & 4.29 & 2.38 \\
\hline Diethyl succinate & 30.842 & Aged & 19.03 & 18.44 & 10.91 & 17.84 & 33.60 \\
\hline 4-ethyldecanoate & 31.207 & Pear and vegetative & - & - & 1.10 & - & - \\
\hline Phenylethyl acetate & 34.012 & Apple and honey & - & - & - & - & 1,02 \\
\hline Hexanoic acid & 35.663 & Animal, waxy, unpleasant & 8.65 & 9.22 & 9.52 & 7.63 & 6.93 \\
\hline Phenylethanol & 37.366 & Roses and honey & 24.44 & 13.91 & 11.79 & 21.25 & 14.50 \\
\hline Diethyl malate & 40.59 & Toffee & - & 0.78 & 0.75 & - & 1.34 \\
\hline Octanoic acid & 41.085 & Waxy and coconut & 40.59 & 37.44 & 46.69 & 35.32 & 9.85 \\
\hline Decanoic acid & 45.998 & Animal, waxy and palm oil & 11.92 & 8.63 & 23.19 & 10.43 & 2.42 \\
\hline Caproleic acid & 47.361 & Waxy or unripe fruit & - & - & - & - & 0.75 \\
\hline Phthalic acid & 54.695 & & - & 0.76 & - & - & - \\
\hline
\end{tabular}

$\dagger$ Retention time. $\ddagger$

Table 2. Most described aromatic descriptors by the Brazilian and Italian panel.

\begin{tabular}{|c|c|c|c|c|c|c|c|c|c|}
\hline Sample & \multicolumn{7}{|c|}{ Aromatic descriptores most citaded by the evaluators, in Brazil and Italia, and number of citations } \\
& \multicolumn{7}{|c|}{ in decreasing order } \\
\hline SW1 BR & Bread 5x & Nuts 5x & Yeast 4x & Roasted 2x & Green Apple 2x & Pear 2x & Herbs 2x & Peach 2x & Pineapple 2x \\
\hline SW1 IT & Bread 5x & Yeast 4x & Fruity 3x & Floral 3x & Roasted 3x & Licour 3x & Deffect 2x & Dry Leaf 2x & Papaya 2x \\
\hline SW2 BR & Peach 4x & Butter 3x & Fruity 3x & Floral 3x & Bread 3x & Citric 2x & Yeast 2x & Roasted 2x & Pineapple 2x \\
\hline SW2 IT & Floral 6x & Yeast 5x & Fruity 4x & Apple 3x & Bread 3x & Herbs 3x & Pear 2x & Deffect 2x & Licour 2x \\
\hline SW3 BR & Floral 4x & Pear 3x & Pineapple 3x & Bread 2x & Roasted 2x & Yeast 2x & Nuts 2x & Citric 2x & Roses 2x \\
\hline SW3 IT & Yeast 7x & Floral 6x & Bread 5x & Fruity 4x & Apple 3x & Pear 2x & Dry Fruit 2x & Licour 2x & Limon 2x \\
\hline SW4 BR & Yeast 4x & Roasted 4x & Bread 3x & Pineapple 2x & Nuts 2x & Deffect 2x & Peach 2x & Fruity 2x & Licour 2x \\
\hline SW4 IT & Fruity 4x & Apple 3x & Bread 3x & Yeast 3x & Pineapple 3x & Herbs 2x & Floral 2x & Roasted 2x & Dry Fruit 2x \\
\hline SW5 BR & Bread 7x & Nuts 5x & Roasted 3x & Citric 3x & Yeast 2x & Pineapple 2x & Herbs 2x & Peach 2x & Floral 2x \\
\hline SW5 IT & Floral 5x & Fruity 4x & Anise 2x & Apple 2x & Bread 2x & Yeast 2x & Deffect 2x & Herbs 2x & Nuts 2x \\
\hline
\end{tabular}

The conditions also included a $250{ }^{\circ} \mathrm{C}$ injector temperature, helium carrier gas at a flow rate of $1 \mathrm{~mL} / \mathrm{min}$, purge-less, splitless injection mode, injection in a VFWAX column, $175^{\circ} \mathrm{C}$ and $150^{\circ} \mathrm{C}$ source and quadrupole temperatures, respectively, and a $280^{\circ} \mathrm{C}$ transfer line temperature. The mass spectrometer operated in SCAN mode (with a scan range of $\mathrm{m} / \mathrm{z} 30-350$ ). The volatile compounds were identified using the NIST 08 Mass Spectral Library and via comparison with the literature. Agilent MassHunter Qualitative Analysis B.06.00 was used for data acquisition and processing, and mean values were calculated using ExcelR 2013.

An open form was used for the sensory evaluation to describe the olfactory portion using the main aromatic descriptors. The Brazilian evaluation panel consisted of
12 evaluators ( 5 men and 7 women) with a background in Enology and at least 3 years of experience in wine evaluation. The Italian panel also comprised 12 trained evaluators (6 men and 6 women) who were participants in a wine tasting group. The evaluators were asked to assign up to 3 aromatic descriptors to describe the perceived aroma of each sample.

The main descriptors of each sample were chosen according to the highest frequency of citation in the panel of evaluators and presented below. The results of the sensory and GC-MS analysis were compared with the data obtained by [12] through the gas chromatography combined with olfactometry (GC-O) of samples of Brazilian sparkling wines to identify correlation between the data. 


\section{Results and discussion}

The association between gas chromatography and mass spectrometry allowed the identification of 26 volatile compounds with diverse sensorial characteristics, which was confirmed by the sensorial analysis of the products.

In the comparison of this result with those found by the use of GC-O, by [12], also in the Brazilian sparkling samples, the results can be correlated, since the author found 25 different areas pointed out by the evaluators.

Table 1 shows the GC-MS results, the list of 26 compounds identified shows the classes of esters, alcohols and volatile fatty acids. Most of the compounds belong to the class of esters, one of the classes with great sensorial impact in wines, with descriptors related to fruity and floral notes [14].

The ester with the highest concentration identified was ethyl acetate, with aromatic descriptor related to fruits such as apple, pear or peach. The highlight was the SW3 sample, with the highest concentration [15] found similar concentrations in Cavas. The second ester found in highest concentration was the ethyl octanoate, related to sweet scents, and again the sample SW3 presented highlight, with concentration more than three times larger than the sample with lower concentration, SW5.

Another ester in which the SW3 sample showed a higher concentration than the others samples was ethyl decanoate, with floral aromatic descriptors, where the concentration represented more than double the second sample with the highest concentration SW2. Other compounds found have similar mean values between samples, such as ethyl hexanoate, isoamyl acetate, identified in samples SW1, SW2 and SW3, and malate diethyl, found in samples SW2, SW3 and SW5. The ethyl lactate presented higher values, in concentration higher than double the other samples, in SW1 and SW4 wines. The isoamyl lactate, related to floral aromas, was only found in the SW3 sample. Finally, the succinate diethyl was present in all samples, being the highlight for the sample SW5, which shows a concentration three times higher than the sample SW3, with lower concentration, [16] indicates that the concentration of this ester increases during the maturation of the sparkling wine.

When comparing the results with those indicated by [12] in GC-O analysis in the Brazilian sparkling samples, it can be established that the esters have a great impact on the sensorial perception of these wines, when we consider that the main descriptors mentioned were related to aromas fruity and floral.

The values found for alcohols such as 1-propanol, isobutanol, and isoamylic are similar to those found by [12], and lower than those published by [17]. The alcohol 1-hexanol presents values up to 5 times higher than those pointed out by [17], which can demonstrate how the climatic characteristic influences Brazilian products. Of the volatile acids identified, the hexanoic acid presented small variation among samples, and is in agreement with the values found by [18] for sparkling wines with periods of up to 12 months of maturation.

Table 2 shows the results of sensory analysis. In the Brazilian panel, 155 determinations of aromas were found in the sparkling wines, with 31 different descriptors. Of the 31 descriptors, a group of 9 descriptors was chosen that were cited more frequently by the evaluators, being: bread, yeast, pineapple, nuts, citrus, herbs, peach, fruity and floral.

In the Italian panel were 188 determinations of aromas found by the evaluators, with 32 different descriptors, of which 9 were chosen by frequency of use, being: fruity, apple, bread, yeast, floral, pear, herbs, pineapple and liqueur.

It is possible to observe similarities between the chosen descriptors, in the two panels. The bread and yeast notes indicate that the characteristic of maturation on lees in Brazilian sparkling wines is perceptible, however, many indicators are of the class of fruity aromas, which make it evident that these sparkling wines are characteristic of freshness and joviality.

The floral and herbal aromas of garden denote that there is a good complexity in the products, coming from the different techniques of production or varieties used in the production. Similar results were found by [12].

When comparing the sensory data with the compounds identified by the GC-MS, it can be observed that the notes related to fruits and flowers have a strong relation with the predominant esters profile in the sparkling wines, such as pineapple, apple, pear, peach and fruit citric acid, described by the evaluators, may be related to the presence of esters such as ethyl hexanoate, ethyl octanoate, isoamyl acetate, ethyl lactate and ethyl decanoate. Results with similar descriptors related to these compounds were presented by other authors, also in wines [19-21].

\section{Conclusions}

1. SPME-GC-MS identified 26 volatile compounds with possible sensorial impact, the majority being esters linked to fruity and floral descriptors.

2. The sensory analysis performed with two panels showed similarity between the evaluations, being the main descriptors to those related to maturation on lees, such as bread and yeast, and fruity and floral aromas, with correlation with the compounds identified by GC-MS.

3. By comparing the two analyzes it can be stated that the profile of the Brazilian sparkling wine is a young product, with a fruity and floral characteristic and notes of maturation.

\section{References}

[1] Q.J. Wang, C. Spence, Food Qual. Preference 68, 238 (2018)

[2] K. Furdíková, L. Bajnociová, F. Malík, I. Spánik, J. Food Nutr. Res. 56, 73 (2017)

[3] K. Chira, N. Pacella, M. Jourdes, P. Teissedre, Food Chem. 126, 1971 (2011)

[4] J.L. Landon, K. Weller, J.F. Harbertson, C.F. Ross, Am. J. Enol. Vitic 59, 153 (2008)

[5] A. Vilela, B. Monteiro, E. Correia, Ciência Téc. Vitiv, 30, 1 (2015)

[6] M.B.M. Castilhos, V.L. Del Bianchi, S. GómezAlonso, E. García-Romero, I. Hermosín-Gutiérrez, Food Chem. 272, 462 (2019)

[7] R. Noguerol-Pato, C. Gonzáles-Barreiro, B. CanchoGrande, J. Simal-Gándara, Food Chem. 117, 473 (2009)

[8] L. Tat, P. Comuzzo, I. Stolfo, F. Battistutta, Food Chem. 93, 361 (2005) 
[9] A. Ziółkowska, E. Wasowicz, H. Jélen, Food Chem. 213, 714 (2016)

[10] M. Diziadas, H. Jelen, Analytica Chimic Acta 677, 43 (2010)

[11] I. Lukic, S. Radeka, N. Grozaj, M. Staver, D. Peršuric, Food Chem. 196, 1048 (2016)

[12] M. Gabbardo, F. Battistutta, E.T. Gabbardo, L. Tat, E. Celotti. BIO Web of Conferences 7, 1 (2016)

[13] D.A. Wurz, R. Allebrandt, B.P. Bem, J. Reinehr, A.T. Canossa, L.G. Damolin, L. Rufato, A.A. Kretzschmar, BIO Web of Conferences 9, 1 (2017)

[14] V. Caliari, V.M. Burin, J.P. Rosier, M.T. Bordignon Luiz, Food Res. Int. 62, 965 (2014)

[15] J. Torres, M. Riu-Aumatell, S. Vichi, E. LópezTammames, S. Buxaderas, J. Agr. Food Chem. 58, 2455 (2010)
[16] J. Bosche- Fusté, M. Riu-Aumatell, J.M. Guadayol, J. Caixach, E. López-Tammames, S. Buxaderas, Food Chem. 105, 428 (2007)

[17] S. Pérez-Magariño, M. Ortega-Heras, L. MartínezLapuente, Z. Guadalupe, B, Aystarán, Eur. Food Res. Technol. 236, 827 (2013)

[18] M.A. Pozo-Bayón, E. Pueyo, P.J. Martín-Álvarez, A.J. Martínez-Rodriguez, M.C. Polo, Am. J. Enol. Vitic 54, 273 (2003)

[19] M. Vilanova, Z. Genisheva, A. Masa, J.M. Oliveira, Microchem. J. 95, 240 (2010)

[20] M.J. Gómez-Míguez, J.F. Cacho, V. Ferreira, I.M. Vicario, F.J. Heredia, Food Chem. 100, 1464 (2007)

[21] R.A. Peinado, J. Moreno, J.E. Bueno, J.A. Moreno, J.C. Mauricio, Food Chem. 84, 585 (2004) 